\title{
Comparison of the Single Breath Vital Capacity Technique with the Tidal Volume Technique
}

\author{
Singh J', Tandukar A ${ }^{2}$, Kharbuja $\mathrm{K}^{3}$
}

\begin{abstract}
Introduction: The single breath vital capacity (VC) induction and the tidal volume (TV) breathing induction are currently administered for inhalation of anaesthesia with sevoflurane in children. The aim of this study was to determine whether the vital capacity technique achieves more rapid induction of anaesthesia in children compared to the conventional tidal volume technique. Material and Methods: Sixty ASA physical status 1 or 2 children aged between 5 and 15 years, scheduled to undergo elective urological, orthopaedic or visceral surgery under general anaesthesia using inhalational induction with sevoflurane were recruited and randomized to receive either vital capacity induction or tidal volume induction with $8 \%$ sevoflurane at $6 \mathrm{~L} / \mathrm{min}$ of $\mathrm{O}_{2}$ followed by laryngeal mask airway insertion or endotracheal intubation with endotracheal tube. Time required for induction, hemodynamic changes, airway tolerance, side-effects, level of satisfaction using a visual analogue scale (0-100) and Smiley scale (0-10) were documented. Results: Induction time was significantly shorter with the vital capacity induction technique than with the tidal volume breathing induction technique $(43.8 \pm 13.4$ seconds vs $70.8 \pm 16.4$ seconds; $P<0.01)$. The time to central myosis, haemodynamic changes and respiratory events incidences were similar in both the group. Fewer complications occurred with vital capacity group. More than $94 \%$ of the children choose the single Breath Vital Capacity method of induction to the tidal volume technique. Conclusion: For inhalation induction of anaesthesia, the vital capacity induction was faster and produced less complication than that of tidal volume breathing technique.
\end{abstract}

Key words: Sevoflurane, Induction, Anaesthesia, Singlebreath vital capacity, Tidal volume breathing

\section{Introduction}

Sevoflurane's low blood gas solubility and sweet smelling means it is able to produce an acceptable induction in children ${ }^{1}$. Rapid induction and emergence from anaesthesia also makes it suitable agent for ambulatory anaesthesia and short surgical procedures. The
${ }^{1}$ Dr. Jeevan Singh, MBBS, MD. Associate Professor and Head, ${ }^{2} \mathrm{Dr}$. Alex Tandukar, MBBS, MD. Lecturer, ${ }^{3} \mathrm{Dr}$. Kalpana Kharbuja, MBBS, MD, Lecturer. All from the Department of Anaesthesia and Critical Care, Kathmandu University School of Medical Sciences, Dhulikhel, Kavrepalanchowk, Nepal.

\author{
Address for correspondence \\ Dr. Jeevan Singh \\ Associate Professor and HOD \\ Department of Anaesthesia and Critical Care \\ Kathmandu University School of Medical \\ Sciences \\ Dhulikhel, Kavrepalanchowk, Nepal. \\ Tel No; +9779851029933 \\ E-mail: drjeevan25@gmail.com
}

Acknowledgements: We would like to thank Dr. Parikshit Bikram Singh, MBBS, Medical Officer, International Friendship Children's HospitalIFCH, Kathmandu, Nepal, Dr. Bibek Shrestha, MBBS, Post Graduate Resident, who helped us with the data collection for this study.

Funding: Nil

Conflict of Interest: None

Permission from IRB: Yes

\section{How to cite}

Singh J, Tandukar A, Kharbuja K. Comparison of the Single Breath Vital Capacity Technique with the Tidal Volume Technique. J Nepal Paediatr Soc 2018;38(2):84-89.

doi: http://dx.doi.org/10.3126/jnps.v38i2.20145

This work is licensed under a Creative Commons Attribution 3.0 License. 
need for a rapid recovery has become more important in day care surgeries are increasing in the children. Rapid and smooth induction of anaesthesia is frequently desirable in children, as long as cardiovascular stability is not compromised ${ }^{2,3,4}$. A slow inhalational induction may be upsetting for a child and excitability is not uncommon during gaseous induction ${ }^{5,6,7}$. Traditional stepwise incremental increases in inspired concentration of sevoflurane as well as single breath vital capacity rapid inhalation induction using immediate high inspired concentration of sevoflurane have been well tolerated in paediatric patients ${ }^{8}$.

Vital capacity induction has advantages over the traditional method, as induction is more rapid and the transition from induction to the maintenance phase is smooth with a lower incidence of excitatory phenomena. Inhalation induction avoids the "hangover" associated with intravenous agents and it can be achieved without intravenous access ${ }^{9}$.

The single breath vital capacity technique is suitable for inhalation of anaesthesia, using sevoflurane in children aged more than five years. It consists firstly of exhaling to residual volume and then with the anaesthetic system and the mask gently applied to the face inhaling to vital capacity followed by a breath hold. This technique has been widely popular in adults since the introduction of sevoflurane ${ }^{10,11,12}$. However, it remains a less practiced technique.

Therefore, this study was designed to determine whether the vital capacity technique achieved more rapid induction of anaesthesia in children compared to the conventional tidal volume technique and, secondly to compare the incidence of adverse events and satisfaction scores of the children using of the children using these techniques.

\section{Material and Methods}

After institutional ethical approval and having written informed parenteral consent, 60 children, ASA physical status I or II, aged $>5$ and $<16$ years, who were scheduled to undergo anesthesia by inhalational of sevoflurane to undergo elective urological, orthopaedic or visceral surgery were enrolled into this prospective open randomized clinical trial.

Children with contra-indication to inhalation induction of anaesthesia (gastro-oesophageal reflux, vomiting, myopathy or familial history of malignant hyperthermia) and those with a history of cardiac function, epilepsy, neurological disease, and asthma, severe or acute respiratory illness/infection during the previous week were not included in this study.
Monitoring included pulse oximetry for haemoglobin oxygen saturation, electrocardiography for heart rate (HR) and non-invasive blood pressure (NIBP), inspired end tidal sevoflurane and carbon dioxide measurement. All instructions were carried out in the supine position by a single anaesthesiologist. The children were instructed the vital capacity technique in a playful manner: "to blow out birthday candles" and then "to inflate the lung and stop breathing as possible as if you had to dive into a swimming-pool".

The paediatric circle-absorber breathing circuit of an anaesthesia machine was primed in standardized conditions with sevoflurane $8 \%$ in 6 litres/minutes fresh gas Oxygen flow. The 2 litre reservoir bag were then evacuated and refilled. After forced exhalation, the child took a single vital capacity breath via a transparent mask connected to the breathing circuit. When the pupils were central, the fresh gas flow will be decreased to 2 litres/ minute and inspired sevoflurane was reduced to $4 \%$.

A successful vital capacity is defined as complete expiration followed by complete inspiration and an immediate period of apnoea with inflated lungs. Apnoea is defined as breath holding for at least $15 \mathrm{~s}$.

Any involuntary movements such as dystonic reactions were characterized by involuntary contractions in opposing flexor and extensor muscles that produce sustained and fixed abnormal postures, such as oculogyric crisis, tongue protrusion, trismus, laryngealpharyngeal constriction, torticollis, or bizarre positions of the limbs and the trunk.

A dedicated observer will review children's opinion using a visual analogue blinded scale graded from 0 to 100 and a modified six-scale scored $0,2,4,6,8$, and 10 where the child pointed the face that shows how much he has liked his induction ${ }^{13}$.

Time for "Loss of Eye Lash reflex" and central pupil was determined as time of putting facemask on patients until the loss of eye lash reflex and constricted pupil respectively.

All results are expressed as mean \pm standard deviation. Student's $t$ test was used for analysis of time to loss of consciousness. ANOVA and Bonferroni tests were used to assess patients' variables and hemodynamic changes. A value of $p<0.05$ was considered to be statistically significant.

\section{Results}

Anaesthesia was induced successfully in all patients. The two groups were similar in terms of age, sex and weight (Table 1) 
Induction of anaesthesia with both the techniques was associated with an increase of approximately $20 \mathrm{mmHg}$ in MAP which occurred within two minutes and persisted for at least the first five minutes of anaesthesia (Fig:1). Heart rate increased slightly compared with baseline after induction of anaesthesia with both the techniques. However HR did not differ significantly between the groups at any time during induction (Fig: 2). There was also no difference in SP02 between the two groups at any time. The median visual score was 9.1 $(8.8-9.4)$ and correlated $(p<0.001)$ with modified scale results $(0=0.5 \%, 2=3 \%, 4=5 \%, 6=10 \%, 8=25 \%, 10$ $=56.5 \%$ of the responses).

Table 1: Demographic data of subjects

\begin{tabular}{cccc}
\hline & $\begin{array}{c}\text { VC group } \\
(\mathbf{n = 3 0 )}\end{array}$ & $\begin{array}{c}\text { TV group } \\
(\mathbf{n = 3 0 )}\end{array}$ & $p$-value \\
\hline Age in months & $112(98-134)$ & $116(94-145)$ & $>0.05$ \\
\hline ASA grade $(\mathrm{I} / \mathrm{II})$ & $24 / 6$ & $27 / 3$ & $>0.05$ \\
\hline Weight in Kg & $32.2 \pm 3.4$ & $33.3 \pm 2.8$ & $>0.05$ \\
\hline Sex ratio(M/F) & $18: 12$ & $20: 10$ & $>0.05$ \\
\hline
\end{tabular}

Induction of anaesthesia was significafaster in the Vital capacity group in time to loss of eyelash reflex, although the mean difference between the two groups was only 8 seconds.

Table 2: Characteristics of the induction

\begin{tabular}{ccc}
\hline Induction characteristics & $\begin{array}{c}\text { VC } \text { group } \\
(\mathbf{n = 3 0 )}\end{array}$ & $\begin{array}{c}\text { TV group } \\
(\mathbf{n = 3 0})\end{array}$ \\
\hline Time to loss of eyelash reflex(s) & $41(15)$ & $49(13)$ \\
\hline Time to central pupils(s) & 212 & 231 \\
\hline Incidence of airway events (\%) & $3 / 30$ & $4 / 30$ \\
\hline Incidences of side effects & $1 / 30$ & $3 / 30$ \\
\hline
\end{tabular}

Table 3: Satisfaction with inhalational technique

\begin{tabular}{ccccc}
\hline & Yes & No & Total & $p$-value \\
\hline VC group & $27(90 \%)$ & $3(10 \%)$ & $30(100 \%)$ & 0.001 \\
\hline TV group & $20(20 \%)$ & $10(80 \%)$ & $30(100 \%)$ & 0.230 \\
\hline
\end{tabular}

Table 4: Incidence of complication during induction of anesthesia

\begin{tabular}{|c|c|c|c|}
\hline & $\begin{array}{l}\text { VC group } \\
(n=30)\end{array}$ & $\begin{array}{c}\text { TV group } \\
(n=30)\end{array}$ & $p$-value \\
\hline Cough & $1(3.3 \%)$ & $4(13.33 \%)$ & 0.02 \\
\hline Laryngospasm & $0(0 \%)$ & $1(3.3 \%)$ & 0.015 \\
\hline Breath hold & $2(6.6 \%)$ & $4(13.3 \%)$ & 0.128 \\
\hline Salivation & $0(0 \%)$ & $0(0 \%)$ & NA \\
\hline Movement(purposeful) & $1(3.3 \%)$ & $3(10 \%)$ & 0.052 \\
\hline Movement(involuntary) & $0(0 \%)$ & $1(3.3 \%)$ & 0.021 \\
\hline Dystonic reactions & $1(3.3 \%)$ & $4(13.3 \%)$ & 0.012 \\
\hline
\end{tabular}




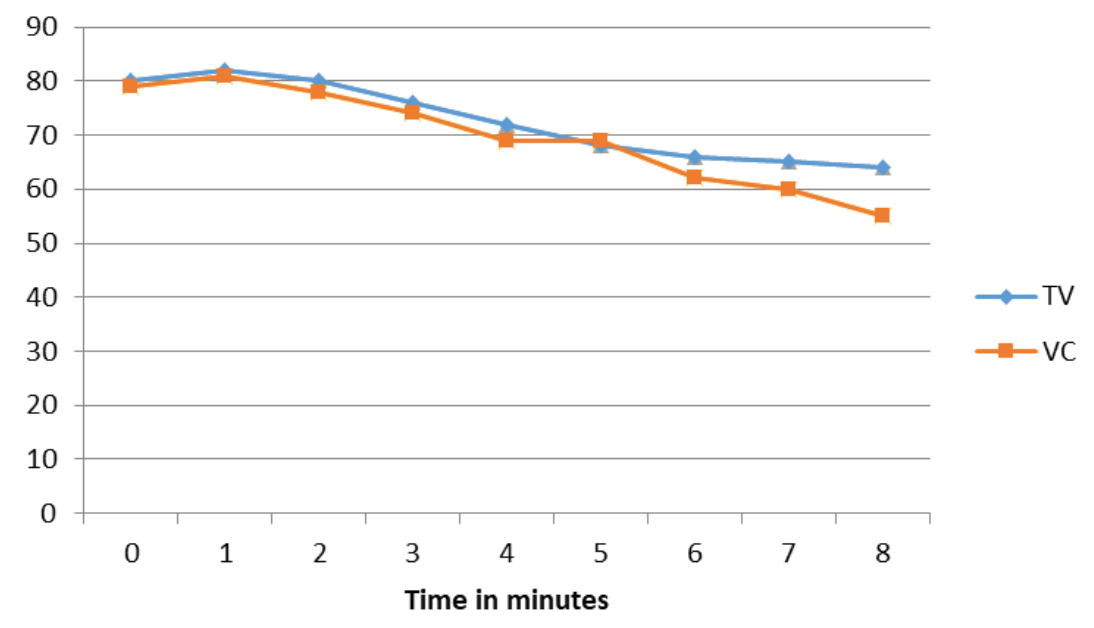

Fig 1: Changes in mean arterial pressure $(\mathrm{mmHg})$ in children undergoing $8 \%$ sevoflurane induction with a tidal volume technique (TV) $(n=30)$ and with a single breath vital capacity $(\mathrm{VC})(n=30)$.

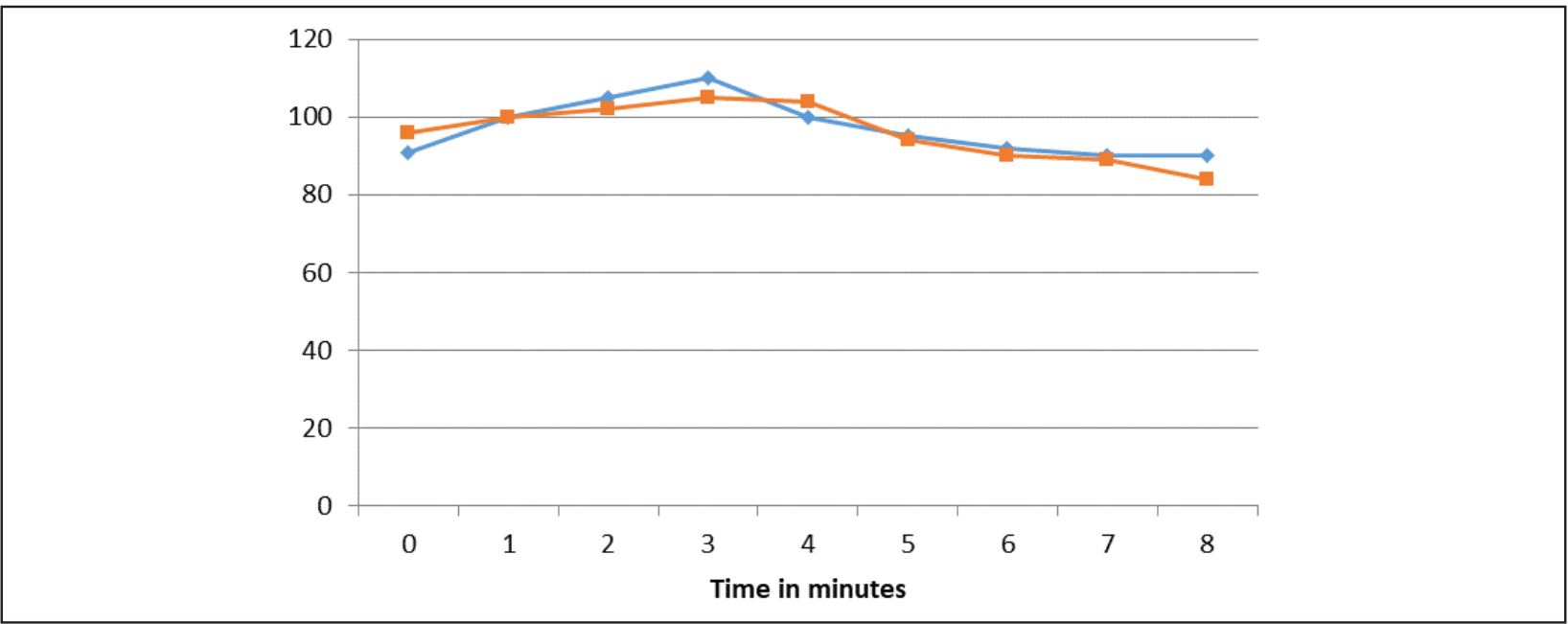

Fig 2: Changes in heart rate (HR) in children undergoing $8 \%$ sevoflurane induction with a tidal volume technique (TV) $(n=30)$ and with a single breath vital capacity (VC) $(n=30)$.

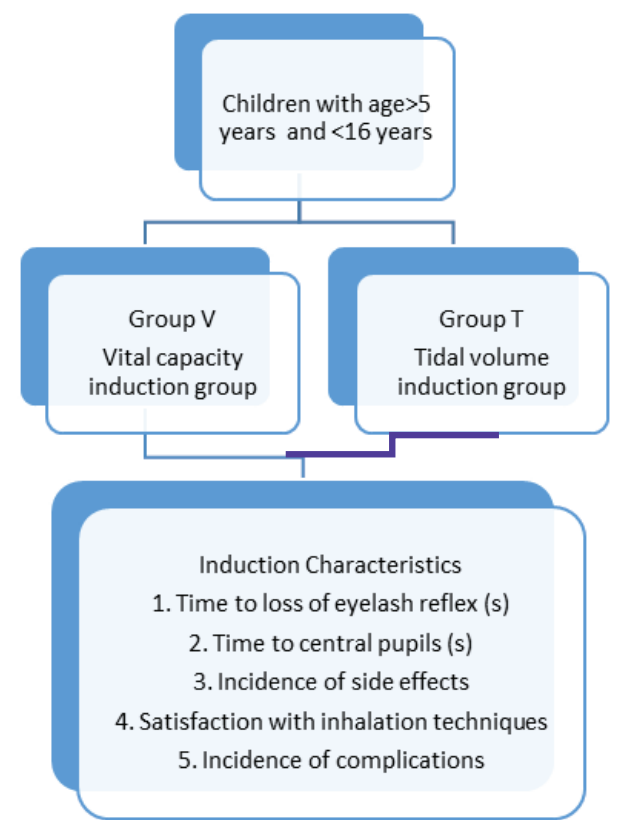

Flowchart of study

J. Nepal Paediatr. Soc. 


\section{Discussion}

The Study demonstrated statistically and clinically significant lower incidences of adverse airway events in the single breath vital capacity technique using $8 \%$ sevoflurane when compared with the conventional tidal volume inhalational technique in the initial phases of anaesthesia. These adverse airway events, although benign and self-limiting have the potential to lead laryngospasm, and thereby produce clinically significant hypoxia.

The single breath vital capacity technique is tolerated well than the more conventional tidal volume inhalational technique. The vital capacity technique produce a more rapid induction of anaesthesia, as assessed by the loss of the eyelash reflex, and was also better tolerated by the children. Although the single breath vital capacity technique produced a more rapid loss of the eyelash reflex, this benefit remains small and the time to produce deep anaesthesia with central myosis was not reduced. Tolerance with single-breath vital capacity was good and side effects were less in comparison to tidal volume breath. Our study showed no hypoxia related to apnoea.

In our study, all patients were able to perform single breaths properly. Exhalation to residual volume minimizes the amount of alveolar air and maximizes the quality of sevoflurane entering the lungs and reaching the alveoli in one breath. Dilution of sevoflurane is reduced and the highest possible alveolar concentration of sevoflurane is maintained. A high-inspired sevoflurane concentration ensures that the alveolar partial pressure of sevoflurane approaches the inspired partial pressure and offsets uptake of sevoflurane by arterial blood in the lungs(concentration effect) ${ }^{14}$.

This study confirms a high rate of success associated with the vital capacity technique and provides evidence that this technique can be used in children aged between 5 and 15 years. The inability of a few children to hold a vital capacity breath has prompted Ho eta/15 to propose a double-breath vital capacity inhalation induction as a faster alternative.

Haemodynamic data were similar to those found in previous studies ${ }^{16}$. The inhibition of parasympathetic control of heart rate by sevoflurane may be responsible for the transitory tachycardia ${ }^{17}$.

Smoothness of induction was significantly improved with VC group. In this study, excitation during induction was low (assessed by quality of induction acceptance score) and this may be an effect of high concentration of sevoflurane. VC induction has been recently compared with TV induction, where VC induction produces significantly more rapid attainment of central pupils, although time to loss of eyelash was not significantly faster with TV induction.

Dystonias were the most frequent complications. They occurred at the beginning of deep anesthesia and were mostly limited to peripheral muscles. Rarely, when localized to cervical muscles ${ }^{18}$, dystonic movements caused spastic torticollis and rotation of the head and could favour airways obstruction as described in one of our patients.

A total of $50 \%$ of the patients who underwent a TV induction technique had one or more complications. On the contrary, induction of anaesthesia with VC technique was associated with a lower complication rate (16.5\%) The incidence of purposeful and involuntary movements during induction was higher with TV technique 3 (10\%) and $1(3.3 \%)$ respectively compared with a VC technique $1(3.3 \%)$ and $0(0 \%)$ respectively $(p<0.05)$. Although not statistically, we noted four patients who held breath during induction while performing the TV technique whereas only two in the VC technique.

\section{Conclusion}

The Single breath vital capacity breathing technique is possible in young children. Induction of anaesthesia is significantly faster with single breath vital capacity technique and is well tolerated in comparison to Conventional Tidal volume technique. Although the single-breath capacity technique with high sevoflurane concentrations seems to accelerate anaesthetic induction compared with tidal volume, further comparative studies with randomization of tidal volume vs vital capacity inhalation technique, are needed in large scale.

\section{References}

1. Cote CJ, Lerman J, Ward RM, Lugo RA, Goudsouzian N. Pharmacokinetics and Pharmacology of Drugs Used in Children. Cote CJ, Lerman J, Todres ID (Editors). In: A Practice of Anesthesia for Infants and Children. $4^{\text {Th }}$ edition. Philadelphia: Saunders. Elsevier's; 2009. Pg 89-146.

2. Dubois MC, Piat V, Constant I, Lamblin O, Murat I. Comparison of three techniques for induction of anaesthesia with sevoflurane in children. Paediatr Anaesth 1999;9(1):19-23. DOI: https://doi.org/10.1046/ j.1460-9592.1999.9120327.x

3. Taivainen T, Tiainen P, Meretoja OA, Raiha L, Rosenberg $\mathrm{PH}$. Comparison of the effects of sevoflurane and 
halothane on the quality of anaesthesia and serum transferase alpha and fluoride in paediatric patients. $\mathrm{Br}$ J Anaesth 1994;73:590-95.

4. Meretoja OA. Taivainen T. Raiha L. Sevofluranenitrous oxide or halothane-nitrous oxide for paediatric bronchoscopy and gastroscopy. Br J Anaesth 1996 Jun; 76(6): 767-71.

5. Black A, Sury MR, Hemington L. A comparison of the induction characteristics of sevoflurane and halothane in children. Anaesthesia 1996;51(6):539-42.

6. Piat V, Dubois M-C, Hohanet S, Murat I. Induction and recovery characteristics and hemodynamic responses to sevoflurane and halothane in children. Anaesth Analg 1994; 79(5):840-84.

7. Sarner JB, Levine M, Davis PJ, Lerman J, Cook DR, Motoyama EK. Clinical characteristics of sevoflurane in children: a comparison with halothane. Anesthesiology 1995;82(1):38-46.

8. Mi-Ja Yun, Hyo-Seok Na, Young Duck Shin, Jun-Sung Han, Jung-Won Hwang, Chong Soo Kim AndJin Ho Bae. A portable inhalation induction device provide provides co-operative induction of anaesthesia in preanaesthetic area for children. Korean J Anesthesiol 2010;58(6):521-26. DOI: 10.4097/kjae.2010.58.6.521

9. Philip BK, Lombard LL, Roaf ER, Drager LR, Calalang I, Philip JH. Comparison of vital capacity induction with sevoflurane to intravenous induction with propofol for ambulatory anesthesia. Anesth Analg 1999;89:623-27. DOI: 10.4103/aer.AER_193_17

10. Yurino $M$, Kimura $H$. Induction of anesthesia with sevoflurane, nitrous oxide, and oxygen: a comparison of spontaneous ventilation and vital capacity rapid inhalation induction (VCRII) techniques. Anesth Analg 1993;76:598-601. DOI: 10.4103/0259-1162.143122

11. Muzi M, Robinson BJ, O'Brien TJ. Induction of anesthesia and tracheal intubation with sevoflurane in adults. Anesthesiology 1996;85:536-43.

12. Hall JE, Stewart JI, Harmer M. Single-breath inhalation induction of sevoflurane anaesthesia with and without nitrous oxide: a feasibility study in adults and comparison with an intravenous bolus of propofol. Anaesthesia 1997;52:410-15.

13. Hicks CL, Von Baeyer CL, Spafford PA et al. The faces pain scale-revised: towards a common metric in pediatric pain measurement. Pain 2001;93:173-83.

14. C. Lejus, V. Bazin, M. Fernandez et al. Inhalation induction using sevoflurane in children: the singlebreath vital capacity technique compared to the tidal volume technique. Anaesthesia 2006;61(6):535-40. DOI: 10.1111/j.1365-2044.2006.04661.x

15. Ho K, Chua WL, Lim S, NGA. A comparison between single- and double-breath vital capacity inhalation induction with $8 \%$ sevoflurane in children. Paediatr Anaesth 2004;14:457-61. DOI: doi/pdf/10.1111/j.13652044.2006.04661.x

16. Lerman J, Sikich N, Kleinman S, Yentis S. The pharmacology of sevoflurane in infants and children. Anesthesiology 1994;80:814-24.

17. Constant I, Dubois MC, Piat V, et al. Changes in electro-encephalogram and autonomic cardiovascular activity during induction of anesthesia with sevoflurane compared with halothane in children. Anesthesiology 1999;91:1604-15.

18. Bernard JM, Le Roux D, Pereon Y. Acute dystonia during sevoflurane induction. Anesthesiology 1999;90:1215-216 